Aguiar, P.W.; Padua, S.M.; Gomes, M.A.O.; Uezu, A. Subsídios para o planejamento de trilha no Parque Estadual da Serra Furada (SC). Revista Brasileira de Ecoturismo, São Paulo, v.3, n.3, 2010, pp.498-527.

\title{
Subsídios para planejamento socioambiental de trilha no Parque Estadual da Serra Furada (SC)
}

\author{
Paula Wronski Aguiar, Suzana Machado Padua, \\ Marcos Affonso Ortiz Gomes, Alexandre Uezu
}

\begin{abstract}
RESUMO
As trilhas interpretativas nas Unidades de Conservação (UCs) surgem como instrumentos educativos bastante utilizados em programas de ecoturismo, uma vez que põem as pessoas em contato com os ambientes naturais, propiciando experiências para a reformulação de valores e atitudes, também desafiando o corpo e permitindo a prática de habilidades físicas pouco exigidas no dia-a-dia. $\mathrm{O}$ objetivo deste trabalho é sugerir o planejamento ambiental da trilha que dá acesso à Pedra Furada no Parque Estadual da Serra Furada, município de Grão-Pará, estado de Santa Catarina. Estudos realizados na região do Parque possibilitaram caracterizar a área e propor uma trilha de visitação aos usuários. A região do entorno do Parque e, em específico, a Comunidade Serra Furada foi estudada por meio de pesquisas de dados secundários e de algumas ferramentas do método de Diagnóstico Rápido Rural (DRR). O planejamento das intervenções propostas neste produto considera os diversos elementos que devem ser integrados para a garantia da segurança, da interação com o meio e do conforto dos visitantes. Sugere-se um programa de capacitação para a Comunidade Serra Furada, capaz de oferecer meios de enriquecer conhecimentos, despertar a consciência de protagonismo, profissionalizando seus integrantes para alcançar eficiência, qualidade e diversidade nos produtos e serviços oferecidos aos turistas. É proposto, também, um sistema de monitoramento e controle de impacto de visitação para a Trilha como alternativa de prevenção de impactos negativos, com o desígnio de manter a integridade e, consequentemente, a qualidade do ambiente natural e do programa oferecido. É esperado que este trabalho possa subsidiar futuras pesquisas e projetos neste Parque Estadual, contribuindo para a conservação e para a sustentabilidade da biodiversidade local, além de oferecer meios de melhorar a qualidade de vida das pessoas locais, a partir da implantação da Trilha Serra Furada.
\end{abstract}

PALAVRAS-CHAVE: Trilhas interpretativas; Conservação Ambiental; Parque Estadual da Serra Furada. 


\title{
Social and environmental subsidies for the planning of the of Parque Estadual Serra Furada trail, SC, Brazil
}

\begin{abstract}
Interpretive trails have been widely utilized as an education tool in protected areas because they give people a chance to directly experience nature, facilitating shifts in values and attitudes, as well as challenging physical abilities not used on a day-by-day basis. The aim of this paper is to suggest an environmental plan for a trail that leads to the Pedra Furada (which means stone with a hole) in Parque Estadual da Serra Furada in the region of Grão-Pará, in the State of Santa Catarina, Brazil. Previous studies in the Park's region allowed us to characterize the area and propose a trail to be used for visitation. The Park's surroundings and more specifically the Serra Furada community were studied through a methodology known as Rapid Rural Assessment. The plan we propose includes several aspects such as security, visitor's interaction with the environment, and their comfort. We suggest a capacity building program for the community of Serra Furada designed to enrich people's knowledge, raise their awareness, and empower them to work effectively and professionally in providing high-quality products and services to tourists. We also propose a system that can monitor the impact of visitation on the trail to guard against negative impacts and maintain the integrity and therefore the quality of the natural environment and of the program being offered. We hope this paper can help future studies and projects that may be conducted at the Park and thus contribute to the conservation and sustainability of its biodiversity, as well as offering ways to improve people's quality of life through the implementation of the Serra Furada Trail.
\end{abstract}

KEYWORDS: Interpretive Trails; Environmental Conservation; Parque Estadual Serra Furada.

\section{Introdução}

Quando as sociedades organizadas começaram a se instalar e a crescer em todas as partes do planeta, o ritmo e a escala das intervenções humanas nos ecossistemas aumentaram. Em virtude dessas pressões de consumo sobre os recursos naturais, os ecossistemas estão sendo degradados, muitas espécies sendo extintas, ciclos naturais sendo alterados, espécies invasoras sendo propagadas e os danos, que agora se evidenciam com as mudanças climáticas que afetam toda a biodiversidade e a própria humanidade.

Entretanto, há décadas atrás, a população em geral vem buscando caminhos para reverter essa crise ecológica na qual nos encontramos atualmente. Esforços vem sendo realizados visando proteger a diversidade biológica existentes nos diversos ecossistemas terrestres e marinhos, aliados a melhoria da qualidade de vida das populações. 
Aguiar, P.W.; Padua, S.M.; Gomes, M.A.O.; Uezu, A.

Com o intuito de promover a integração das comunidades com a conservação da biodiversidade, governos, empresas, pesquisadores e outros têm iniciado programas de ecoturismo em parques e áreas naturais, como forma de promover um turismo responsável a partir de um conjunto de normas que ajudem a proteger a integridade ambiental, e ao mesmo tempo melhoram a qualidade de vida das populações do entorno dessas áreas.

A este propósito, várias são as medidas que ajudam a tornar uma visita a áreas naturais uma experiência enriquecedora. Dentre elas, se destacam as trilhas interpretativas em programas ecoturísticos, como atividades que visam manter a integridade ambiental por meio da sensibilização do visitante para a importância de se proteger a natureza. As trilhas promovem a aproximação das pessoas com os ambientes naturais, propiciando experiências que estimulam o repensar de atitudes predatórias, a favor de novos comportamentos frente às questões ambientais. Auxiliam, do mesmo modo, a incluir a participação das comunidades locais em diversas frentes, inclusive nos processos de decisões das atividades, contribuindo para aumentar os sentimentos de orgulho, de auto-confiança e auto-estima dessas populações.

O planejamento das trilhas interpretativas como parte de estratégias para a conservação da biodiversidade e benefícios às comunidades locais requer amplos estudos e trabalhos que envolvam participação dos diversos atores sociais contidos na região em questão, análise de leis e políticas, diagnósticos da área protegida, das comunidades e suas demandas, assim como pesquisas para a elaboração de um programa adequado a cada realidade.

Com base nesses princípios, em 2008, foi iniciado um estudo para o planejamento socioambiental de uma trilha localizada no Parque Estadual da Serra Furada, em Grão-Pará, Santa Catarina, a fim de viabilizá-la para visitação, constituindo parte integrante de contribuições para o Programa de Uso Público da Unidade de Conservação (UC). Este trabalho pretende, assim, fornecer subsídios válidos para futuras intervenções no Parque Estadual da Serra Furada, como forma de aproveitamento do potencial ecoturístico da UC.

Sendo assim, o objetivo é propor o planejamento ambiental de uma trilha interpretativa que dá acesso à Pedra Furada no Parque Estadual da Serra Furada, com fins educativos, recreativos e socioeconômicos, garantindo o uso público da UC, a valorização de espécies nativas da fauna e da flora e a integração desta área natural com a comunidade do entorno. Os objetivos específicos abrangem aspectos sociais e ambientais, e compreendem os seguintes tópicos:

- Caracterizar a Trilha Serra Furada;

- Propor o planejamento ambiental da Trilha;

- Sugerir mecanismos para o desenvolvimento do ecoturismo de base comunitária, por meio do envolvimento da comunidade Serra Furada; 
- Recomendar estratégias para a implantação de ações de Interpretação Ambiental;

- Propor sistema de monitoramento e controle de impactos de visitação da triIha, juntamente com indicação de ferramentas e instrumentos necessários para sua implantação.

\section{Referencial Teórico}

O modelo industrial com base no consumo indiscriminado tem levado a pressões insustentáveis sobre os recursos naturais, que já ultrapassam a capacidade de suporte do próprio sistema natural do mundo em que vivemos, tanto em relação à sua capacidade de recompor para que continue fornecendo o que precisamos, quanto para absorver os resíduos que geramos. Groom et al. (2006) acreditam que, aumentando o número de seres humanos e os níveis de consumo, criam-se condições que ameaçam a existência de toda a biodiversidade dos ecossistemas terrestres e aquáticos, e a própria humanidade.

No entanto, especialmente a partir da década de 70 , conferências e acordos têm sido realizados a fim de discutir as causas das atividades humanas e suas consequências no meio ambiente, visando proteger o patrimônio natural e cultural da humanidade, de modo a garantir a satisfação das necessidades das presentes e das futuras gerações.

Nesse sentido, cada vez mais a atenção é voltada para as áreas naturais e sua proteção, com o intuito de promover a integração das comunidades com a valorização da biodiversidade, tendo em vista a melhoria da qualidade de vida das pessoas e, consequentemente, o desenvolvimento local sustentável, aliado à conservação da natureza.

As áreas naturais protegidas, também chamadas Unidades de Conservação (UCs), são espaços ambientais que têm importantes características naturais e "existem para assegurar a diversidade biológica e os recursos genéticos" (WWFBRASIL, 2008), protegendo as espécies, preservando e restaurando a diversidade nos ecossistemas naturais, fornecendo importantes serviços para todas as formas de vida da Terra.

De acordo com a Lei Federal 9.985 de 2000 (MEDAUAR, 2007, p. 969),

Art. $2^{\circ}$ - As Unidades de Conservação são espaços territoriais e seus recursos ambientais, incluindo as águas jurisdicionais, com características naturais relevantes, legalmente instituídos pelo Poder Público, com objetivos de conservação e limites definidos, sob regime especial de administração, ao qual se aplicam garantias adequadas de proteção. 
Aguiar, P.W.; Padua, S.M.; Gomes, M.A.O.; Uezu, A.

O aumento das pressões antrópicas exercidas no meio ambiente tornou as áreas protegidas ferramentas efetivas para a conservação da biodiversidade. As UCs representam a condição básica para a conservação e a perpetuação da diversidade biológica, contribuindo igualmente para a manutenção dos modos de vida das culturas tradicionais associada à proteção da natureza (SÃO PAULO, 2009, p. 18).

Nessa perspectiva, para proteger efetivamente as áreas naturais e garantir uma gestão adequada, cabe adotar um modelo de desenvolvimento intitulado por "ecodesenvolvimento", proposto por Maurice Strong e Ignacy Sachs, em 1970. Quer seja chamando de ecodesenvolvimento ou desenvolvimento sustentável, esse modelo segue um caminho fundamentado na conservação da biodiversidade, na medida em que visa à harmonização dos objetivos econômicos, sociais e ambientais. $\mathrm{O}$ ecodesenvolvimento é definido como "uma estratégia para a proteção de áreas ecologicamente valiosas, em face às pressões insustentáveis, ou inaceitáveis, resultantes das necessidades e atividades dos povos que vivem nelas ou no seu entorno (SINGH, 1997 apud SACHS, 2002, p. 72).

O esforço para se alcançar o ecodesenvolvimento, segundo Sachs (2002, p. 72-73), é feito em três sentidos: primeiro, cultivando a conscientização da comunidade quanto ao valor e à necessidade de proteção da área, assim como os padrões de sustentabilidade de um crescimento local apropriado; segundo, envolvendo as pessoas que vivem no entorno das áreas protegidas nos planos de conservação e na gestão da área; e, por fim, identificando, citando e desenvolvendo alternativas sustentáveis de recursos de biomassa e renda.

No primeiro item, "cultivando a conscientização da comunidade", é cabível citar a educação ambiental (EA) como "uma proposta de filosofia de vida que resgata valores éticos, estéticos, democráticos e humanistas" (DUAILIB, 2007, p. xii). Este resgate de valores torna-se fundamental num momento da história da humanidade que enfrenta realidades indesejadas, carentes de conhecimentos e esclarecimentos acerca da complexidade da vida, necessitando encontrar caminhos hábeis para a solução dos problemas.

A EA, então, indica esses caminhos para um despertar de consciência que internaliza a compreensão dos direitos de todos os seres vivos, contribuindo para o reconhecimento e importância do protagonismo nas relações do ser humano com a natureza. Segundo Padua (2001), somente quando as pessoas compreenderem o seu valor individual, elas poderão acreditar em seu potencial transformador. Sendo assim, pode-se dizer que a EA propõe acrescentar conhecimentos para mudar valores e comportamentos, encorajando e "empoderando" os diferentes atores sociais que compõe a coletividade moderna na busca de uma sociedade sustentável e democrática.

O segundo item proposto pelo ecodesenvolvimento, "envolver as pessoas que vivem no entorno das áreas protegidas", recomenda promover o engajamento das comunidades locais no processo de gestão, tanto das próprias UCs como das regiões onde moram. Sachs (2004, p. 61-62) diz que as populações devem ter espaços onde 
possam discutir, tomar decisões e aprender a expressar suas opiniões e desejos, sendo empoderadas para que assumam um papel ativo na sociedade. O novo paradigma deve visar esse empoderamento das populações locais e a abertura para a democracia, acontecendo através do diálogo, das negociações e de acordos entre os atores sociais envolvidos.

Aos grupos sociais, antes excluídos das tomadas de decisões, devem ser dados espaços democráticos, de modo a terem a chance de se manifestar e, assim, gerar maior inclusão social a partir da ativa participação. A comunidade pode, então, resolver muitos de seus problemas sem a interferência de outros, inclusive governos, desde que sejam municiados de instrumentos participativos que levem à transformação. As populações locais precisam de informações, que muitas vezes dependem de capacitações, treinamentos, orientações específicas, que possibilitem ganhos de auto-confiança e informação, para que possam tornar-se co-gestoras de suas localidades, lidando de forma consciente e construtiva com os crescentes desafios que a sociedade e a vida moderna apresentam.

O terceiro item, "identificando, citando e desenvolvendo alternativas sustentáveis de recursos de biomassa e renda", tem significado especial para o Brasil, que possui uma das maiores biodiversidades do Planeta, sendo que "nenhum outro país do mundo reúne condições igualmente favoráveis à criação gradual de uma nova civilização sustentável dos trópicos" (SACHS, 2004, p. 130). Em vista disso, há a necessidade de se identificar as habilidades e as potencialidades das populações tradicionais, a fim de se promover o desenvolvimento local através da utilização sustentável dos recursos naturais. Para tanto, "podemos considerar a unidade familiar como possuidora de uma reserva potencial de tempo de trabalho a ser aproveitada como uma verdadeira reserva de desenvolvimento" (SACHS, 2004, p. 125). O autor ainda afirma que "o não-aproveitamento desta reserva de desenvolvimento constitui um grave erro de estratégia, já que o êxodo rural prematuro e excessivo gera problemas de difícil solução no meio urbano".

Para se alcançar essa sustentabilidade social e ambiental, associadas ao crescimento econômico, aponta-se o ecoturismo. O ecoturismo é "um segmento da atividade turística que utiliza, de forma sustentável, o patrimônio natural e cultural, incentiva sua conservação e busca a formação de uma consciência ambientalista através da interpretação do ambiente, promovendo o bem-estar das populações envolvidas" (EMBRATUR, 1994 apud WWF-Brasil, 2003, p. 12).

Dessa forma, governos, organizações não-governamentais (ONGs), sociedade civil e instituições do setor privado têm desenvolvido programas de ecoturismo em parques e áreas naturais, como forma de promover um turismo responsável. Isto representa um conjunto de normas que ajudem a proteger a integridade ambiental, e, ao mesmo tempo, melhoram a qualidade de vida das populações do entorno dessas áreas.

Para a The Nature Conservancy (DRUMM; MOORE, 2002, p. 15), o ecoturis- 
Aguiar, P.W.; Padua, S.M.; Gomes, M.A.O.; Uezu, A.

mo beneficia tanto a população local quanto as áreas protegidas em questão, tornando-se uma estratégia globalmente utilizada de desenvolvimento sustentável. Nesse sentido, o "turismo sustentável", como também é denominado, utiliza os recursos naturais como atrativos turísticos causando o mínimo de impacto negativo. Além disso, inclui as comunidades locais nas tomadas de decisões, respeitando culturas e tradições, gerando benefícios de ordem econômica às pessoas que ali habitam, bem como promovendo intrinsecamente a educação e a interpretação ambiental.

Dentro dos programas de ecoturismo, as trilhas interpretativas são importantes atividades que propiciam o contato dos seres humanos com a natureza. Proporcionam benefícios às comunidades locais e a reformulação de um novo pensar sobre as questões complexas da vida. Uma trilha pode, pois, ser definida como "via estreita, usualmente não-pavimentada e intransitável para veículos de passeio" (ASSOCIAÇÃO BRASILEIRA DE NORMAS TÉCNICAS, 2007, p. 2).

De simples local de locomoção, as trilhas surgem como um meio de interpretação ambiental, visando o contato com a natureza, com fins de transmissão de conhecimentos, sensibilização e formação de uma consciência ecológica. Além de ser uma forma de recreação tranquila, econômica, prazerosa e sadia, oferece ainda oportunidades de observação e pesquisa da biodiversidade.

Quando bem elaboradas, as trilhas conseguem promover o contato mais estreito entre o ser humano e a natureza, possibilitando conhecimento das espécies animais e vegetais, da história local, da geologia, da pedologia, dos processos biológicos, das relações ecológicas, ao meio ambiente e sua proteção, constituindo instrumento pedagógico extremamente importante. Uma trilha, se positivamente planejada, também promove mudanças de valores, princípio básico da educação ambiental, além de criar desafios ao corpo, e "pode ser um grande laboratório para a reformulação da questão do individualismo nos processos coletivos" (MENDONÇA; NEIMAN, 2002, p. 163).

\section{Caracterização da área de estudo}

O Parque Estadual da Serra Furada (PESF) foi criado pelo Governo de Jorge Konder Bornhausen pelo Decreto $n^{\circ} 11.233$, de 20 de junho de 1980, na condição de Unidade de Conservação do Grupo de Proteção Integral, e é gerido pela Fundação do Meio Ambiente de Santa Catarina (FATMA). Sua área é de aproximadamente 1.329 ha e está situado entre as Coordenadas Geográficas de $49^{\circ}$ $25^{\prime} 59^{\prime \prime}$ de Longitude Oeste e de $28^{\circ} 07^{\prime} 03^{\prime \prime}$ e $28^{\circ} 11^{\prime} 41^{\prime \prime}$ de Latitude Sul (figura 1), nos Municípios de Orleans e Grão-Pará, Estado de Santa Catarina. 

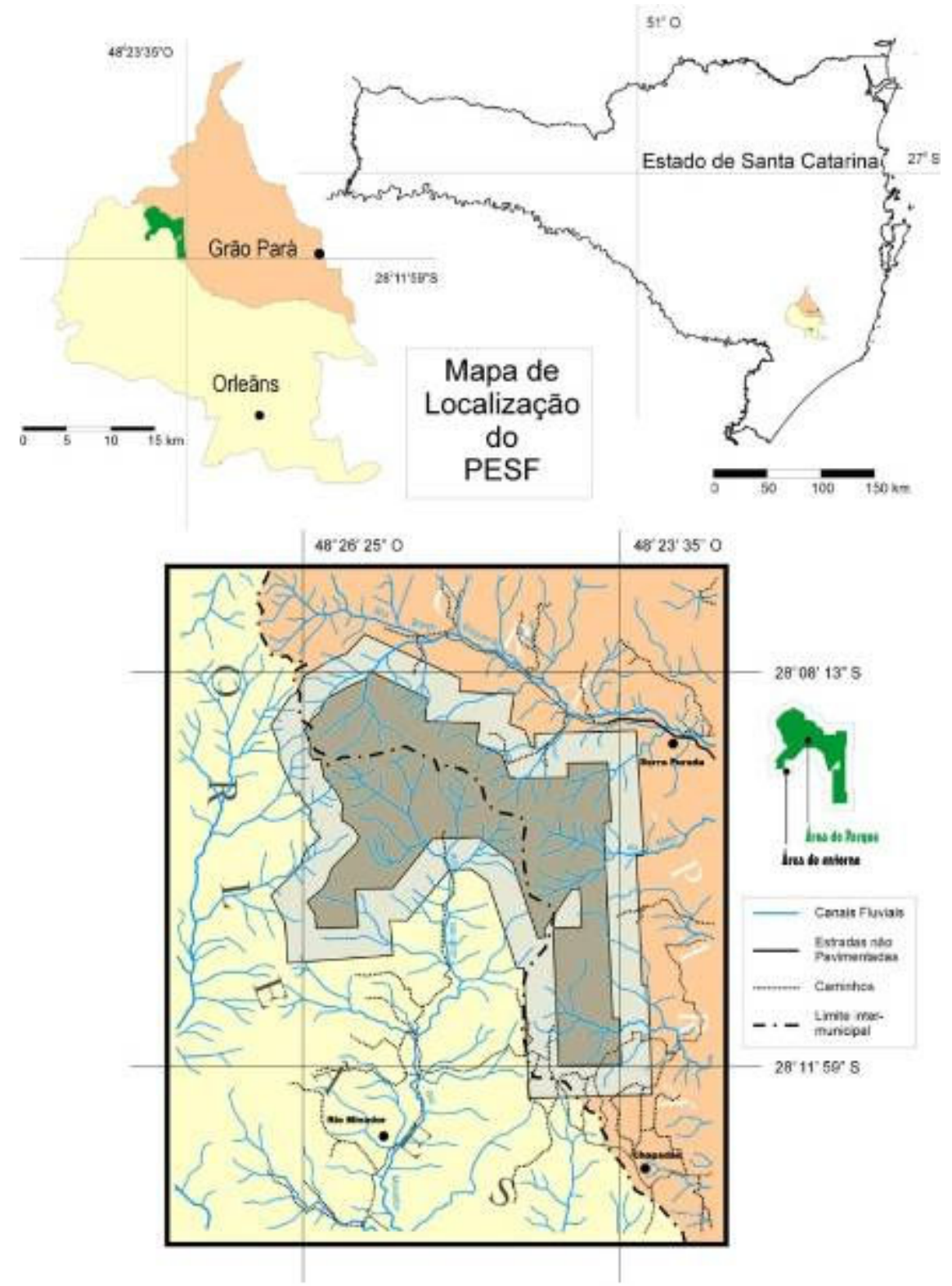

Figura 1 - Localização do Parque Estadual da Serra Furada.

Fonte: Termo de Referência do Parque Estadual da Serra Furada.

Segundo o Programa Integrado de Desenvolvimento Sócio-Econômico - PIDSE (1990), a região de estudo apresenta o relevo constituído de uma planície de superfície plana e ondulada, também conhecida como planície meridional ondulada ou planície meridional no pé da Serra Geral. De acordo com o Relatório Técnico (2008, p. 41), a área do Parque está situada na região fitoecológica da Floresta Atlântica, envolvendo as formações Submontana, Montana e Altomontana, entremeados por áreas 
Aguiar, P.W.; Padua, S.M.; Gomes, M.A.O.; Uezu, A.

de refúgios vegetacionais rupestre, nos paredões abruptos onde afloram as formações areníticas do arcabouço geológico.

Segundo o PIDSE (1990), a área está inserida na Região Hidrográfica Sul Catarinense, apresentando como principais cursos de água as bacias dos rios Tubarão e D'uma. O município de Orleans tem como principais afluentes os rios Braço do Norte, Novo, Cachorrinhos, Laranjeiras, Pinheiros, Palmeiras e Capivaras. O município de Grão-Pará é banhado pelos rios Espraiado ou Pequeno, Braço Esquerdo, Capivaras, Cachoeirinha e Pequeno. O Parque apresenta como seus principais afluentes os rios Braço Esquerdo, Laranjeiras, Minador e rio do Meio.

O clima da região, segundo Koppen, classifica-se como mesotérmico úmido, sem estação seca, com verões quentes. A temperatura média anual varia entre $18,8^{\circ}$ C a $19,2^{\circ} \mathrm{C}$, sendo a temperatura máxima de $35^{\circ} \mathrm{C}$ e a temperatura mínima de $-5^{\circ} \mathrm{C}$. A precipitação total anual varia entre 1.300 e $1.600 \mathrm{~mm}$. As geadas são constantes no inverno.

De acordo com o Relatório Técnico (2008), as atividades de agricultura estão predominantemente na área de entorno da UC, nos patamares submontano e montano, constituindo a somatória de cultivos agrícolas, onde se sobressaem lavouras de fumo. As áreas de reflorestamento estão concentradas predominantemente nos patamares submontano e montano, sendo constituídas predominantemente com espécies do gênero Eucalyptus e, eventualmente, do gênero Pinus, em diferentes idades, desde recém-implantados até em fase de corte final.

\section{Metodologia}

Para a elaboração do planejamento socioambiental da Trilha utilizou-se de estratégias de saídas de campo, entrevistas com as comunidades do entorno da UC e pesquisa de dados secundários (Figura 2).

\section{Saídas de campo na trilha}

Por já existir um trajeto, não foi necessária a eliminação da vegetação para a abertura de novos caminhos. A Trilha foi mapeada utilizando um GPS da marca GARMIN, que forneceu a altitude e as coordenadas geográficas em latitude e longitude. Para a tomada dos pontos foi observada a mudança das condições da Trilha e de sua direção. No programa Google Earth, os pontos obtidos com o GPS deram origem ao traçado da Trilha.

A caracterização das condições da Trilha foi baseada no Manual de Ecoturismo de Base Comunitária do WWF-Brasil (2003) e no projeto de Vashchenko (2008), incluindo algumas adaptações. A Trilha foi subdividida por vegetação atual, classe de solo e declividade. Em cada trecho foi indicada a posição no relevo, a altitude, descrita a 

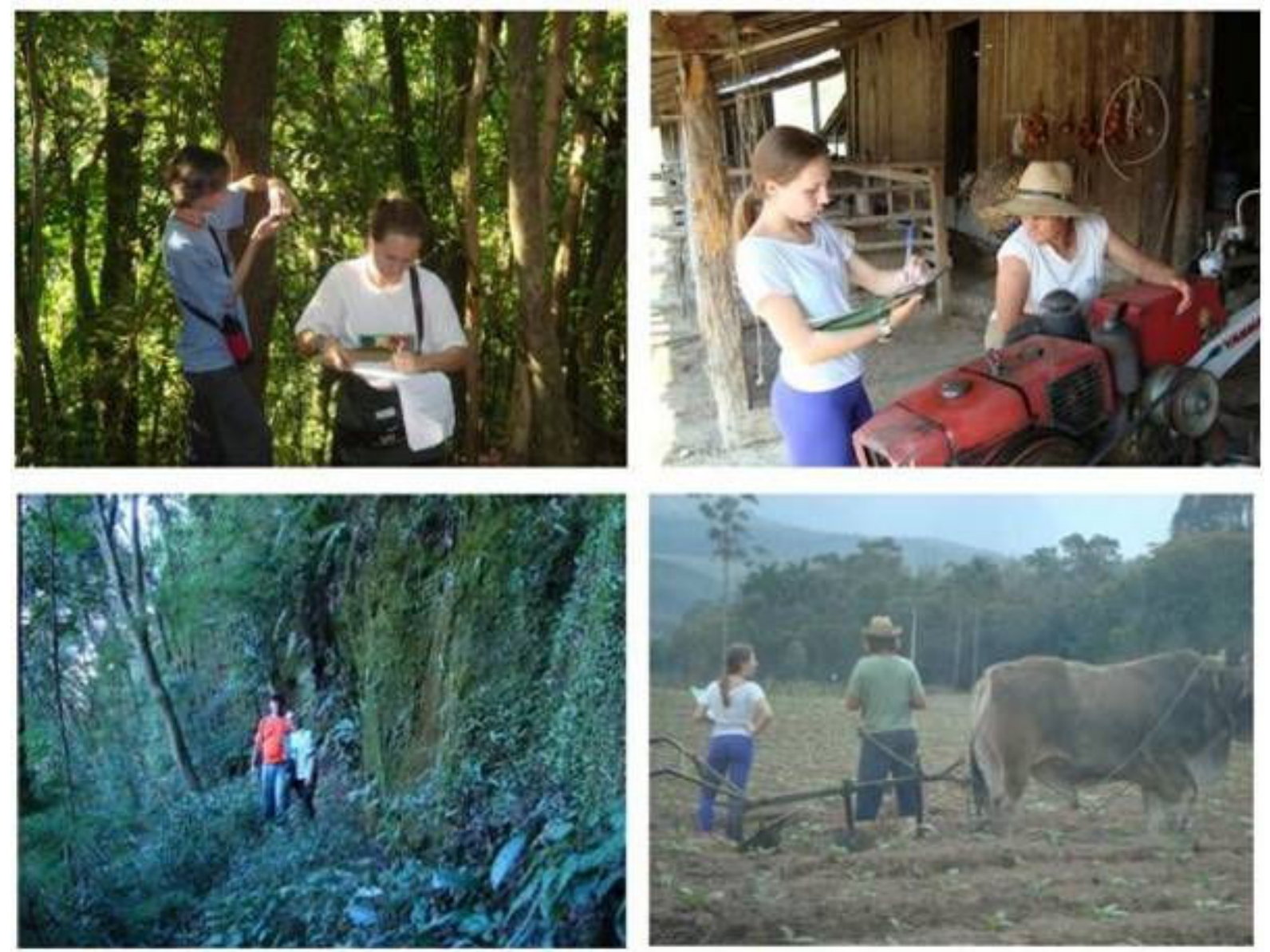

Figura 2 - Atividades de pesquisa e saídas de campo.

formação de degraus e a formação de sulcos, avaliada a cobertura da vegetação do dossel, a cobertura da serrapilheira, a exposição do solo, de raízes e de rochas, medida a espessura da serrapilheira e a largura da Trilha. A caracterização das condições da Trilha foi realizada como descrito a seguir:

- Vegetação: A vegetação foi determinada conforme a altitude do trecho, sendo caracterizadas as formações: submontana, ou do início das encostas, com altitude abaixo de $500 \mathrm{~m}$; montana, ou do meio das encostas, com altitude de 500 a $1000 \mathrm{~m}$; e, altomontana, ou do alto das encostas, com altitude acima de $1000 \mathrm{~m}$;

- Posição no relevo: A posição no relevo em que o segmento avaliado da Trilha se encontra foi indicada observando o relevo e a declividade, seguindo a seguinte classificação: relevo plano com declividade de 0 a 5\%; relevo ondulado 
Aguiar, P.W.; Padua, S.M.; Gomes, M.A.O.; Uezu, A.

com declividade de $5 \%$ a $20 \%$; e, relevo montanhoso com declividade de $20 \%$ a $70 \%$;

- Declividade: O aparelho chamado Clinômetro foi utilizado para se obter a declividade média dos trechos da Trilha;

- Formação de degraus: O termo formação de degraus foi utilizado para indicar situações onde a Trilha apresentar aspectos parecidos com uma escada, merecendo ser trabalhada com essa característica. A formação de degraus foi classificada como ausente, quando não observado nenhuma necessidade de degrau; pouco presente, quando observados que degraus ocorrem ocasionais; e muito presente, quando observados degraus contínuos em todo o segmento avaliado;

- Formação de sulcos: A descrição de sulco foi usada quando visualmente foi constatado que o aprofundamento do leito ocorreu em consequência de enxurradas. A formação de sulcos foi classificada como ausente, quando não foi observado nenhum sulco; pouco presente, quando os sulcos eram ocasionais e muito presente, quando evidenciados sulcos contínuos em todo o segmento;

- Cobertura da vegetação do dossel: A cobertura da vegetação do dossel foi representada pela projeção das folhas e galhos das copas das árvores mais altas sobre a Trilha e estimada a partir de fotografias tiradas no sentido vertical, onde as áreas escuras da fotografia retrataram a cobertura da vegetação. Os resultados foram classificados considerando a cobertura de $100 \%$ quando a fotografia ficava totalmente escura e $0 \%$ quando totalmente clara.

- Cobertura da serrapilheira: A cobertura da serrapilheira representa o acúmulo de matéria morta e não decomposta fornecida pelas árvores (folhas, galhos, e outros) sobre o solo. A cobertura da serrapilheira foi estimada visualmente, considerando cobertura de $100 \%$ quando todo o segmento avaliado apresentava serrapilheira e $0 \%$ quando nenhum ponto do segmento da Trilha continha serrapilheira. A espessura da serrapilheira foi medida com uma trena.

- Exposição do solo: A exposição do solo foi considerada como consequência da eliminação da cobertura natural. A exposição do solo foi estimada visualmente, considerando exposição de $100 \%$ quando todo o segmento avaliado apresentava solo exposto e $0 \%$ quando nenhum ponto do segmento da Trilha estava exposto;

- Exposição de raízes: A exposição de raízes de espécies arbóreas foi considerada como consequência do aumento da profundidade do leito da Trilha devido à perda de solo. A estimativa foi realizada visualmente, considerando exposição de $100 \%$ quando todo o segmento avaliado apresentava raízes expostas e $0 \%$ quando nenhum ponto apresentava raízes expostas. 
- Exposição de rochas: A exposição de rochas foi estimada visualmente, considerando $100 \%$ quando todo o segmento avaliado apresentava rochas expostas e $0 \%$ quando nenhum ponto do segmento da Trilha continha rochas expostas;

- Largura: A largura foi considerada como a distância entre as margens do leito da Trilha e determinada com uma trena;

- Extensão: A extensão aproximada da Trilha e de seus segmentos foi obtida com a utilização do software TrackMaker Versão 4.3.350, com o qual foi medida a distância entre os pontos obtidos com o GPS no mapeamento da TriIha.

\section{Entrevistas com as comunidades do entorno do parque}

No mês de março de 2009, algumas comunidades do entorno da UC foram diagnosticadas, a fim de definir aspectos socioambientais relevantes que pudessem contribuir para a elaboração do estudo na região. Para tanto, foram utilizadas técnicas de Diagnóstico Rápido Rural (DRR) com entrevistas semi-estruturadas que continham questões abertas, com o intuito de investigar o perfil das comunidades com suas principais atividades econômicas, seus conhecimentos relacionados à UC, os problemas enfrentados na localidade, assim como a identificação de perspectivas e anseios.

Nos meses de julho a setembro de 2009, a comunidade Serra Furada foi entrevistada de modo a diagnosticar seu conhecimento sobre turismo e ecoturismo e o desejo das pessoas desenvolverem atividades relacionadas ao turismo, bem como identificar opiniões, expectativas e receios. As entrevistas também focaram nos conhecimentos relacionados à Trilha Serra Furada e aos turistas que frequentam a região. Assim, foram aplicadas técnicas de Diagnóstico Rápido Rural (DRR) com entrevistas estruturadas e semi-estruturadas baseadas no questionário sugerido pelo Manual de Ecoturismo de Base Comunitária do WWF-Brasil, adaptado pela autora.

\section{Pesquisa de dados secundários}

Para complementar os dados obtidos in loco, foram realizadas pesquisas bibliográficas em livros, artigos e internet, com o intuito de obter informações relacionadas ao planejamento, como por exemplo: fauna e flora da região; topografia e habitat; variações climática; características de drenagem do solo; aspectos técnicos como a probabilidade de volume de uso futuro e características históricas e culturais. Além disso, as pesquisas ajudaram a identificar obras que serão necessárias para a implantação do programa ecoturístico e a sinalização da Trilha proposta.

\section{Cálculo da capacidade de carga da Trilha}

Com base no Manual de Ecoturismo de base comunitária do WWF-Brasil (2003), calculou-se a capacidade de carga da Trilha Serra Furada, a fim de se estabelecer um limite de visitações, evitando-se impactos negativos que tragam ameaças e 
riscos à UC.

Determinação da Capacidade de Carga Física (CCF). A CCF estima a capacidade máxima que uma trilha tem de receber visitas, baseado no seu comprimento, distância entre grupos e no período em que fica aberta à visitação. Segundo Mitraud (2003, p. 328), a CCF é calculada da seguinte forma:

CCF $=\frac{\mathrm{s}}{\text { s.v. }} \times \frac{\mathrm{T}}{\mathrm{t.v.}}$

Onde:

S - Superfície total da trilha, ou seja, a distância total entre o começo e o fim da trilha.

s.v. - Superfície ocupada por um visitante (1m linear é o padrão mais comumente empregado, independente da real largura da trilha), adicionado do espaço ideal entre grupos de 10 pessoas, de forma que um grupo não interfira na experiência do outro com ruídos ou visualização ao longo da trilha.

T - Tempo total em que a área está aberta para visitação pública.

t.v. - Tempo necessário para percorrer a trilha (nesse caso, conta-se apenas o trecho de ida porque está-se contando a superfície total da trilha apenas uma vez).

Com base nessas premissas, a capacidade de carga física (CCF) da Trilha Serra Furada foi estimada levando-se em conta as características e experiências locais. O resultado consiste no seguinte:

- Os grupos serão compostos por 10 a 12 integrantes (incluindo o monitor);

- Um percurso de duas horas é estimado para se subir até a Pedra Furada;

- O horário permitido à utilização será das 8 às 16 horas, portanto 8 horas;

- A distância total entre o começo e o fim da Trilha é de $880 \mathrm{~m}$.

- Cada grupo ocupa $120 \mathrm{~m}$ de trilha, pois se considera, segundo Mitraud (2003), que uma pessoa ocupa $1 \mathrm{~m}$ linear de trilha adicionada o espaço ideal entre grupos.

Logo, a CCF da Trilha Serra Furada é de 20 visitas por dia.

Determinação da Capacidade de Carga Real (CCR). A CCR reduz a CCF com base em diversos fatores limitantes do ambiente ou específicos de cada área. De acordo com Mitraud (2003, p. 329), a CCR é calculada da seguinte forma: 


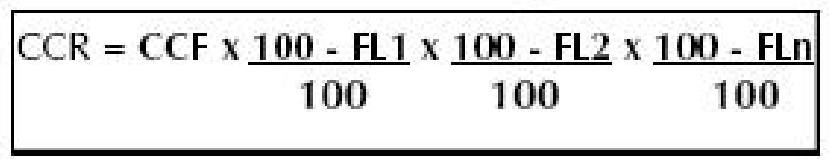

Onde:

FL1 a FLn - Fatores limitantes da capacidade de carga física, ou seja, fatores que limitarão o número de pessoas que terão acesso a determinada Trilha, podem ser: biofísicos (vulnerabilidade a erosão de acordo com declividade e tipo de solo; distúrbio na fauna; dificuldade de acesso etc.), ambientais (precipitação, intensidade de sol, etc.), e de manejo (fechamentos para manutenção, entre outros).

Calculam-se os fatores limitantes para a trilha com a seguinte fórmula:

$$
\mathrm{FL1}=\frac{\text { q.I. }}{\text { Q.T. }} \times 100
$$

Onde:

q.I. - Quantidade limitante do fator considerado (ex.: horas de sol intenso por mês por ano; metros de trilha em alta declividade com solo argiloso; período de reprodução de pássaros etc.).

Q.T. - Quantidade total em que se considera o fator limitante (ex.: total de horas por mês e ano do parque aberto; total de metros da trilha; total de meses etc.).

Para a Trilha Serra Furada, calcula-se:

Fator limitante para a alta declividade: Q.T. é $880 \mathrm{~m}$ (extensão total da trilha) e q.I. é $330 \mathrm{~m}$ (extensão dos trechos que apresentam alta declividade), logo o FL é $37,5 \%$.

A CCR no caso desta Trilha foi definida pela capacidade de carga física menos $37,5 \%$ de seu valor para os trechos que apresentam alta declividade. Logo, a CCR é 13 visitas por dia.

Determinação da Capacidade de Carga Efetiva (CCE). Esta etapa leva em conta que uma área tem outras atividades além da visitação pública, sendo necessário estabelecer os recursos humanos, físicos e financeiros que, de fato, serão consumidos para o manejo da visitação. Mitraud (2003, p. 333) mostra que a CCE pode ser calculada com a seguinte formula: 
Aguiar, P.W.; Padua, S.M.; Gomes, M.A.O.; Uezu, A.

$$
\mathrm{CCE}=\mathrm{CCR} \times \frac{\mathrm{CM}}{100}
$$

Onde:

CM - Capacidade de manejo da área é um número encontrado por meio da elaboração de duas listagens: primeiramente, listagem de todos os recursos humanos, de equipamentos e de infra-estrutura necessários para a implementação de toda a área protegida.

A seguir, contam-se os recursos disponíveis de acordo com a listagem de todos os recursos humanos, de equipamentos e infra-estrutura. A CM será igual à porcentagem da capacidade instalada em relação à capacidade adequada:

$$
\mathbf{C M}=\frac{\text { Capacidade Instalada }(\mathrm{Cl})}{\text { Capacidade Adequada }(\mathrm{CA})} \times 100
$$

De acordo com Mitraud (2003, p. 333), a multiplicação por 100 aponta um resultado em porcentagem. Ou seja, o resultado final é a capacidade de manejo como uma porcentagem da capacidade adequada.

No caso da Trilha Serra Furada, recomenda-se que esta etapa seja concluída com o gestor e os funcionários que mantém o Parque, a partir da implantação do Plano de Manejo, a fim de garantir o correto e exato cálculo de sua Capacidade de Carga Efetiva. Isto se explica porque alguns dados somente serão contabilizados nos processos de implementação de uma gestão efetiva dos recursos da UC.

\section{Caracterização da Trilha}

A Trilha Serra Furada está localizada no Parque Estadual da Serra Furada PESF, mais precisamente na comunidade de Serra Furada, no município de GrãoPará/SC, situada entre as coordenadas geográficas de $49^{\circ} 23^{\prime} 05^{\prime \prime}$ de longitude oeste e de $28^{\circ} 09^{\prime} 00.2^{\prime \prime}$ de latitude sul (Figura 3). $\mathrm{O}$ acesso à Trilha se dá em via terrestre pela estrada geral que liga o centro urbano de Grão-Pará às comunidades São Camilo e Serra Furada.

A atividade que pode ser realizada na Trilha Serra Furada é a caminhada. De acordo com o Ministério do Turismo (BRASIL, 2008, p. 23), as caminhadas são percursos a pé para fins de contemplação, observação e interpretação da natureza. A Trilha possui 880 m de extensão, considerada, segundo Andrade e Rocha (2008, p.6), 
Subsídios para o planejamento de trilha no Parque Estadual da Serra Furada (SC).

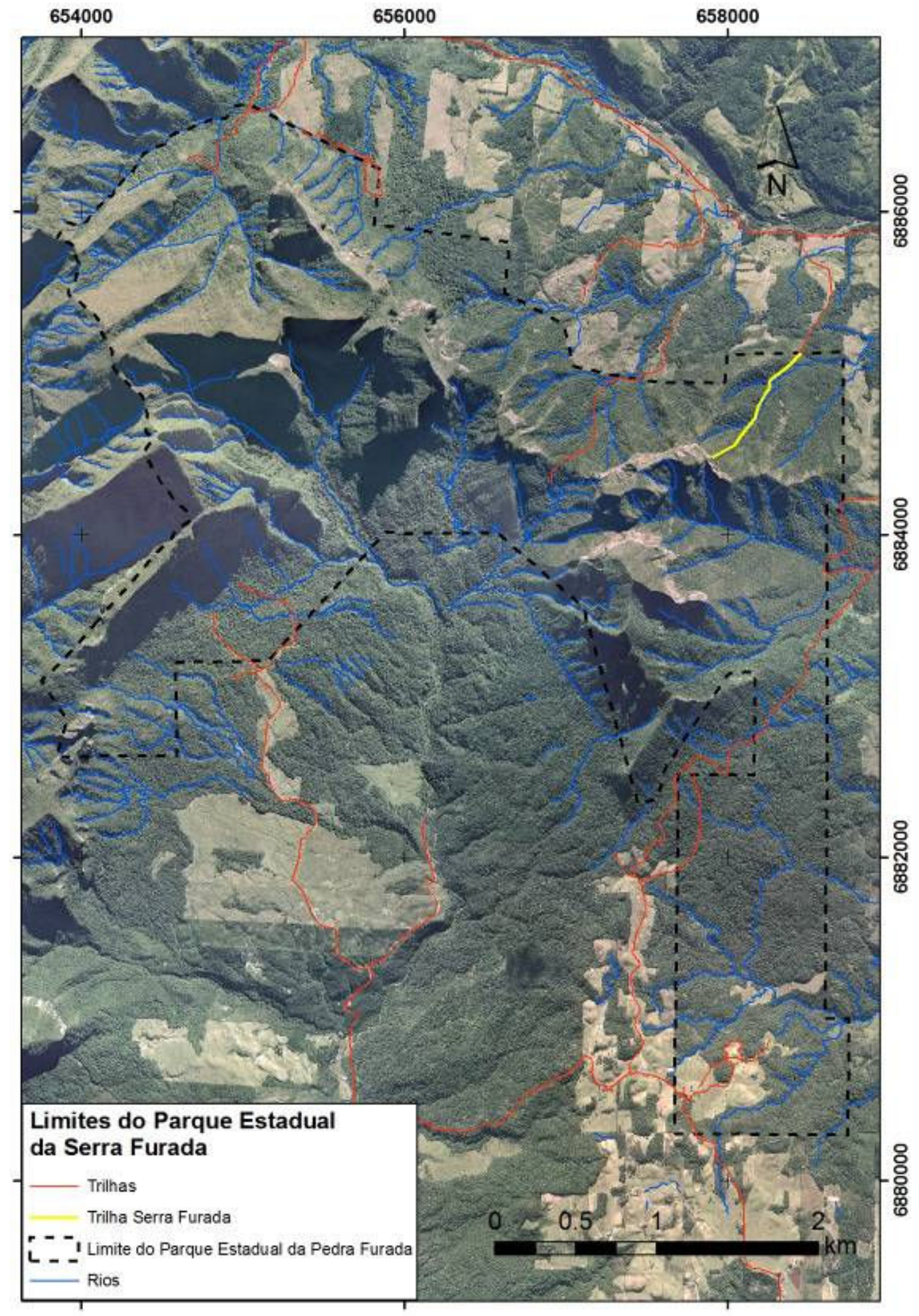

Figura 3 - Fotografia aérea do Parque Estadual da Serra Furada, com destaque para a Trilha. 
Aguiar, P.W.; Padua, S.M.; Gomes, M.A.O.; Uezu, A.

uma caminhada de curta distância. O percurso da Trilha Serra Furada é do tipo linear, cujo objetivo é conectar o caminho principal à Pedra Furada, uma fenda em uma formação basáltica gigantesca, com $45 \mathrm{~m}$ de altura e $8 \mathrm{~m}$ de largura. A Trilha pode ser percorrida (contando ida e volta) em aproximadamente três horas. Como existem aspectos variados a serem observados, o visitante poderá se estender mais ou menos de acordo com o seu foco de interesse.

Há trechos da Trilha que apresentam declividade variando de 10 e $60 \%$, pois que, de acordo com Dias et al. (1986 apud ANDRADE; ROCHA, 2008, p. 11), a Trilha apresenta graus de dificuldade que variam de média, difícil e muito difícil em alguns trechos. Segundo Andrade (2003, p. 249), dentre as categorias leve, regular e semipesada, a Trilha Serra Furada classifica-se como caminhada semi-pesada e pesada em alguns trechos. São consideradas caminhadas semi-pesadas e pesadas, as caminhadas em terreno que variam entre acidentados ou muito acidentados, além de terem inclinações, às vezes, extremamente fortes. Assim, a Trilha Serra Furada exige habilidade específica por apresentar alta declividade em alguns trechos, que requer do visitante um bom condicionamento físico. Sendo assim, a Trilha destina-se a montanhistas e praticantes de esportes radicais, ou seja, jovens e adultos com bom preparo físico. Incluem-se usuários eventuais de fim-de-semana, grupos escolares, cientistas e pesquisadores, dentre outros, que busquem o contato com a natureza, assim como atividades de aventura.

Para o diagnóstico social das 12 famílias da comunidade Serra Furada, foram aplicadas algumas ferramentas de Diagnóstico Rápido Rural (DRR) por meio de entrevistas estruturadas e semi-estruturadas, com base no questionário sugerido pelo Manual de Ecoturismo de Base Comunitária do WWF-Brasil (2003) e adaptado pela autora.

Segundo o diagnóstico, todos os entrevistados são agricultores e alguns também trabalham com o reflorestamento, obtendo uma renda mensal que varia de um salário mínimo (atualmente de $R \$ 460,00$ ) até $R \$ 3.000,00$ (três mil reais), dependendo do mês e/ou ano. Na agricultura, destacam-se as plantações de fumo, milho, feijão, cana, verduras e frutas. Na criação de animias, há galinhas e gado. No reflorestamento, predomina a plantação de eucalipto e pinus.

Dentre dos problemas enfrentados pela comunidade, destacam-se, especialmente, o desemprego, as condições da estrada, a presença de deficientes na família, o deficit habitacional com mais de uma família morando na mesma casa, pela falta de moradias, a falta de antena para telefone e celular, dificuldade de atendimento dos primeiros socorros e escassez em manter a alimentação básica, decorrente da baixa renda como média geral.

Todos os entrevistados têm conhecimento da existência da Trilha no PESF, porém, apenas quatro deles já a percorreram. A partir dos relatos, é possível estimar que a Trilha já é conhecida e percorrida há mais de 40 anos. Dentre as intervenções a serem feitas na Trilha, foram propostas: sinalização; medidas de segurança como degraus, corrimões, dentre outros; e, escada "chumbada" nas rochas que sobem para a 
pedra furada.

Se eles pudessem opinar ou interferir no desenvolvimento do turismo em sua comunidade, dez entrevistados estimulariam o turismo da região, um o proibiria e um não faria nada. E por fim, quando perguntados sobre suas opiniões e desejos, os entrevistados apontaram prioritariamente as melhorias na estrada, dragagem/drenagem do rio, pois já houve inundações na área, palestras para instruir as pessoas quanto ao entendimento e esclarecimentos sobre o PESF, turismo e ecoturismo, educação ambiental, agronegócio, produção e comercialização de produtos locais e guias. Foram mencionados ainda o incentivo à agricultura por parte do governo, a importância do apoio da administração municipal, a geração de mais empregos e a colocação de antena para celular.

A caracterização dos turistas foi baseada em entrevistas e conversas com os atores locais do município de Grão-Pará, incluindo integrantes da comunidade Serra Furada, dentre outros atores sociais, pois a FATMA não tem um controle de visitação do Parque. Segundo relatos, a maior parte dos visitantes advem do entorno regional, principalmente Grão-Pará, Braço do Norte, Tubarão, Criciúma e outros, e, até mesmo, de outras partes do país. Os turistas têm baixo poder de compra, caracterizando-se por mochileiros ou excursionistas, que investem pouco dinheiro ou não gastam nada ao percorrer a trilha. A idade predominante dos visitantes está na faixa de 15 a 35 anos, a maioria estudantes de $2^{a}$ e $3^{a}$ séries do Ensino Médio, além de adultos com bom condicionamento físico. Informam também que, na maioria das vezes, os turistas já conhecem alguém da comunidade para lhes orientar o caminho da Trilha e outras visitas. Não foram identificadas atividades ou interesses específicos dos excursionistas, mas deduz-se que se trata de "ecoturistas "hard" (aqueles com espírito de aventura e melhor preparo físico)" (JANÉR e MOURÃO, 2003, p. 153). A forma de viajar se dá individualmente, isto é, chegam com seus carros próprios ou motos. O período de maior fluxo de visitação ocorre nos fins-de-semana e na época de inverno.

\section{Planejamento ambiental da Trilha Serra Furada}

A Trilha Serra Furada tem o objetivo de conectar o caminho principal à Pedra Furada, atrativo principal do PESF, proporcionando aos visitantes a oportunidade de obter experiências recreativas e educativas por meio do contato e interpretação da natureza.

As intervenções propostas para a Trilha (Figura 4) são: colocação de placas de sinalização e placas interpretativas (Figura 5), visando à segurança dos excursionistas e contribuir para entendimento da área visitada; construção de obras de "reorganização" de drenagem, de modo a facilitar o escoamento da água que se acumula no caminho; construção de contenção de encosta abaixo da Trilha em segmento que apresente deslizamento de terra; colocação de ponte ou pinguela para o segmento que contiver de exposição de rocha; e, clareamento do corredor da trilha, objetivando de facilitar a passagem do turista pelo caminho. 
Aguiar, P.W.; Padua, S.M.; Gomes, M.A.O.; Uezu, A.
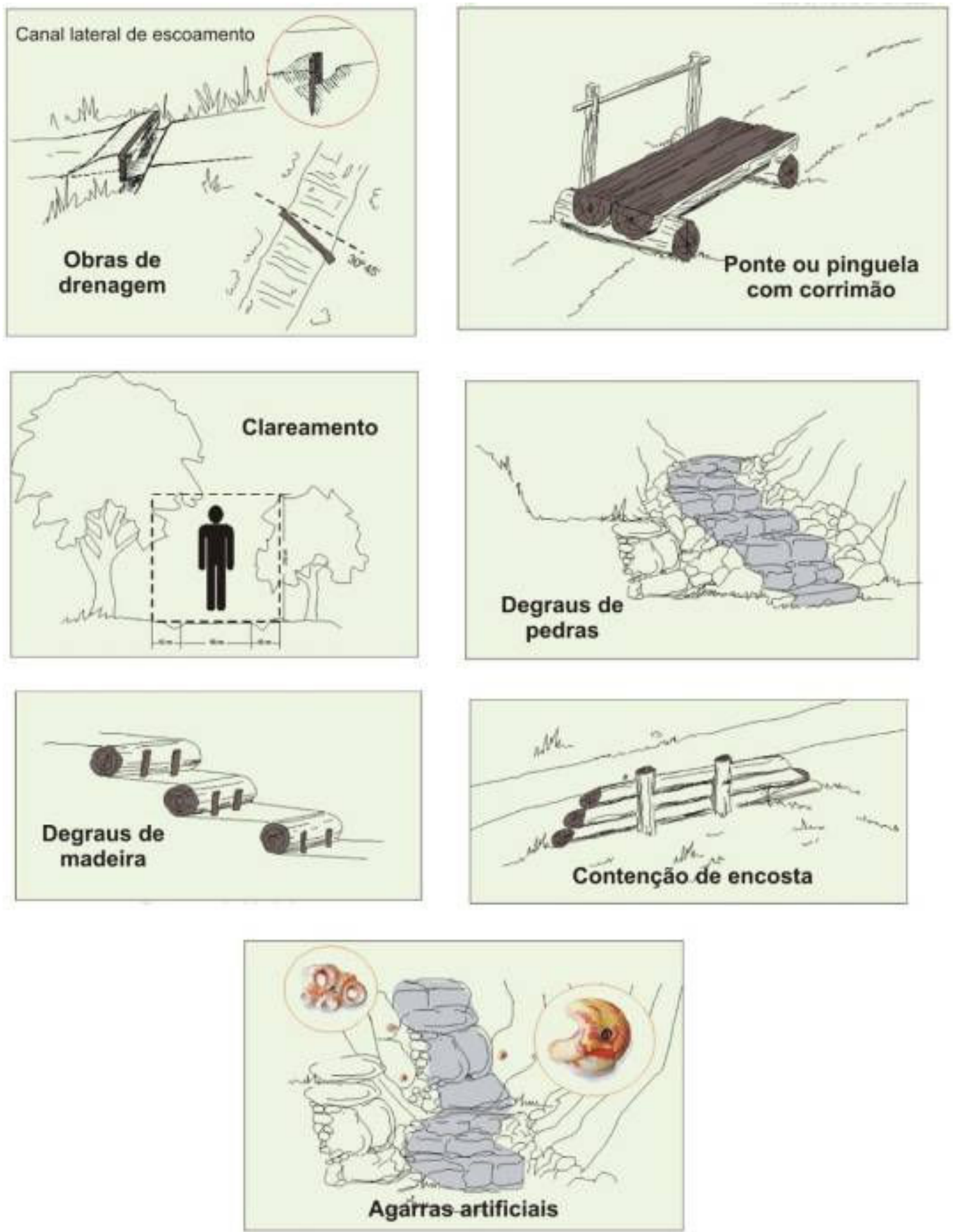

Figura 4 - Intervenções sugeridas para a Trilha Serra Furada. Fonte: Manejo de trilha. Disponível em: <www.ilhabela.org/trilhas/Prop Manejo.doc>. Acesso em: 4 jun 2009. 

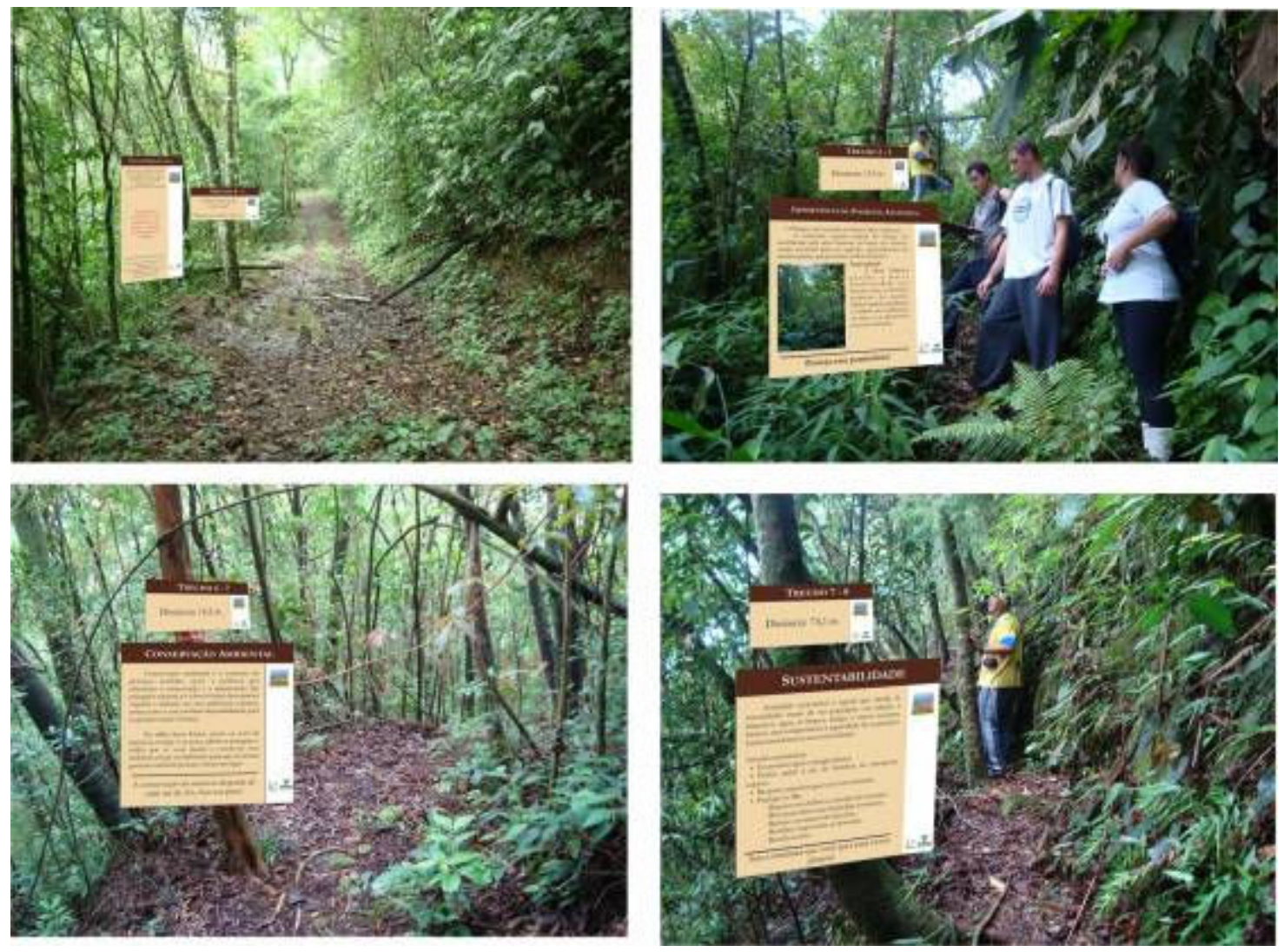

Figura 5 - Fotografias com montagem gráfica das placas de sinalização e educativa.

Para os trechos com alta declividade, indica-se duas alternativas. A primeira é abrir novos trechos que sigam as curvas de níveis do terreno, pois em trechos com alta declividade é necessário construir trilhas em "s" ou em ziguezague, para evitar que os visitantes sigam a linha de queda do terreno. A segunda opção é aproveitar o trajeto que já existe e, nesse caso, sugere-se a edificação de degraus ao longo dos trechos, como alternativa de ganhar considerável elevação em curta distância. Podese ainda colocar cordas para auxiliar na subida e agarras artificiais para evitar que os excursionistas machuquem ou danifiquem a vegetação. A fim de proporcionar maior segurança e conforto aos visitantes, sugere-se a construção de corrimão e/ou guardacorpo - estrutura de proteção requerida quando há exposição a desníveis acentuados e perigosos.

No último trecho da Trilha, recomenda-se que sejam colocadas escadas na própria rocha para facilitar o acesso dos visitantes à Pedra Furada, ou seja, pode ser "assentado uma escada sobre a laje exposta, sendo muito bem chumbado à rocha, com pinos metálicos" (HESSELBARTH et al., 2009, p. 129). Outra indicação pode constar de subidas na rocha da Pedra Furada com o auxílio de equipamentos de escaladas. No entanto, tais escaladas com equipamentos só devem ser permitidas com a ajuda de profissionais, para se evitar acidentes. 
Aguiar, P.W.; Padua, S.M.; Gomes, M.A.O.; Uezu, A.

Com relação à infra-estrutura, recomenda-se a construção de uma recepção turística para atender aos visitantes, junto ao local do estacionamento ou próximo à entrada da Trilha. A finalidade dessa recepção será a de fornecer informações pertinentes aos excursionistas, ou seja, orientá-los sobre todas as condições da Trilha, bem como armazenar e disponibilizar equipamentos importantes para a caminhada. Propõe-se, também, a construção de sanitários, desde que sejam construídos com fossa cética ou que tenham tratamento dos efluentes e dos resíduos sólidos, assim como reaproveitamento dos mesmos na forma de adubo. Outra sugestão é de se colocar lixeiras para coleta seletiva do lixo gerado pelos visitantes.

Ao longo da plantação de Eucaliptos por onde se caminha para chegar à Trilha Serra Furada, aconselha-se a construção de mirante para que as pessoas que não querem percorrer a trilha possam, ao menos, desfrutar da paisagem. "O mirante é uma estrutura para proporcionar segurança durante a observação de uma determinada cena" (ANDRADE, 2005, p. 137).

Como forma de divulgação da Trilha, sugere-se a promoção por meio de folhetos informativos que poderão ser distribuídos a nível estadual, por ser uma forma simples e útil para divulgação. Propõe-se, também, a promoção da Trilha por meio de vídeo informativo sobre o que poderá ser visto no seu percurso, sobre a região e seu entorno.

\section{Planejamento social para a Comunidade Serra Furada}

De modo a alcançar o ecoturismo de base comunitária na Trilha Serra Furada, faz-se necessário um processo democrático e participativo de formação da população local quanto à aquisição de diversos conteúdos relacionados diretamente aos serviços envolvidos nessa atividade. Considerando-se a temática e seus desdobramentos apontados nos diagnósticos realizados com a comunidade Serra Furada, propõe-se as primeiras ações para a implementação de um processo democrático e participativo de formação, com temas de cursos que enriquecem o programa de capacitação para o ecoturismo na região.

Segue abaixo as palestras e cursos sugeridos para a comunidade.

Entendimento e esclarecimentos sobre o Parque. Para dar início ao processo participativo na comunidade Serra Furada é fundamental apresentar esclarecimentos relacionados ao Parque Estadual da Serra Furada, incluindo sua função, objetivos, limites e limitações. A partir do momento em que integrantes da comunidade entendem as reais possibilidades de um projeto, incluindo o conhecimento das limitações da região, certamente terão condições de se tornarem co-gestores locais, uma vez que poderão opinar, decidir conjuntamente e fazer escolhas, contribuindo para melhorias econômicas, sociais e ambientais. 
Introdução ao turismo e ecoturismo. O primeiro curso proposto à comunidade local deverá abordar questões com informações pertinentes a investimentos no ecoturismo, contemplando àqueles que pensam em gerenciar pequenos negócios ou serviços. Os temas deverão incluir noções básicas de turismo e ecoturismo, hospitalidade, contexto regional, nacional e internacional do turismo. Deverão conter, também, a crescente demanda por produtos ecoturísticos, a importância do bom atendimento que inclua a receptividade ao turista e a forma como o visitante é recebido localmente. A história local deverá fazer parte do conteúdo programático, assim como aspectos e peculiaridades que caracterizam o Parque, como a própria Pedra Furada. A idéia é compartiIhar informações que aumentem a auto-estima e o orgulho tanto do morador quanto do visitante pela própria região.

Guias locais. Torna-se essencial promover instruções para as pessoas que desejam se tornarem condutores de um programa ecoturístico, em especial guias de uma trilha interpretativa, como a que está sendo ora proposto. O guia é definido como "monitor ou condutor de visitantes, não credenciado pelo Instituto Brasileiro de Turismo - EMBRATUR" (WWF-Brasil, 2003, p. 433). Sugere-se, portanto, desenvolver capacitação com algumas pessoas integrantes da Comunidade Serra Furada, a fim de capacitálos para a condução dos turistas. Nesse processo, o curso de guias pode envolver conceitos da própria atividade, orientação e condução de grupos, bem como outras áreas do conhecimento, tais como: aspectos da fauna e flora locais; geologia e geomorfologia; história natural e história de ocupação da região; técnicas de primeiros socorros; busca e resgate; e, noções de interpretação ambiental.

Produção e comercialização de produtos locais. Nos diagnósticos com a comunidade Serra Furada, pôde-se identificar que os itens que são produzidos nas lavouras e hortas dos proprietários (milho, feijão, batata, aipim, frutas e derivados do leite), assim como os artesanatos confeccionados pelas mulheres, que incluem bordados e toalhas, podem ser ofertados aos turistas. Assim, os cursos de capacitação para esta região devem focar na melhoria do que é feito localmente, levando aos produtores conhecimentos que envolvem desde a fase de produção, processamento e armazenamento dos produtos, até noções de organização social, vendas e mercado. Pode-se dividir as pessoas em grupos distintos, dependendo do interesse pelo que desejam produzir. Por exemplo, um grupo poderá ser o Clube de Mães, que já tem disponibilizado alguns cursos para a confecção de bordados e toalhas. Outro grupo poderá ser composto por agricultores que demandam outros conhecimentos relacionados ao agronegócio. Ainda, outro grupo pode ser de pessoas que se interessam por artesanatos diversos. Todos devem conter conhecimentos sobre organização comunitária, transparência, apresentação adequada dos produtos para venda e marketing em maior escala.

Outros cursos. O programa de capacitação deve ser flexível, na medida em que atenda as demandas locais. Certamente surgirão outras necessidades não contempladas nesse trabalho, contudo, a propositura é de um programa de capacitação contínuo, adequando-se às exigências locais e às necessidades identificadas no decorrer da implantação do ecoturismo com base comunitária proposto para o PESF. 
Aguiar, P.W.; Padua, S.M.; Gomes, M.A.O.; Uezu, A.

\section{Interpretação ambiental}

O objetivo da interpretação ambiental da Trilha Serra Furada é mediar a aquisição de conteúdos conceituais (biológicos, ecológicos e sociais, etc.), atitudinais e valorativos aos visitantes. No caso deste estudo, os temas que podem ser abordados na Trilha são: localização da área protegida, aspectos biológicos e geológicos, história de ocupação humana, assim como noções de conservação ambiental e sustentabilidade.

Dentre os tipos de trilhas interpretativas que podem ocorrer no Parque Estadual da Serra Furada, é possível citar a trilha auto-guiada até o ponto 3 e trilha guiada daí para frente.

De acordo com as possibilidades coletadas in loco, há a possibilidade dos excursionistas percorrerem a Trilha até o ponto 3 sem o auxílio de um condutor, desde que o percurso seja bem sinalizado (Figura 6), proporcionando a devida segurança a todos durante o trajeto. A trilha auto-guiada é definida por Vasconcelos (2003) como a visita em áreas naturais, com pontos de paradas marcados onde o visitante, auxiliado por placas, painéis ou por folhetos contendo informações em cada ponto, descobre e explora o percurso sem a ajuda de um guia.

$\mathrm{Na}$ trilha guiada, a visita requer a presença de um intérprete treinado, que acompanha os visitantes na caminhada, levando-os a observar, sentir, experimentar, questionar e descobrir os fatos relacionados ao tema estabelecido (VASCONCELOS, 2003 , p. 277). Rocha et al. (2006 apud ANDRADE; ROCHA, 2008, p. 6) afirmam que, trilha guiada compreende a visita ao ambiente natural com o acompanhamento de um guia capacitado para conduzir uma boa comunicação entre o visitante e a natureza, oferecendo segurança a todos na caminhada. Por conta da declividade e características acidentadas de partes do percurso da Trilha, os visitantes ficarão mais seguros se acompanhados de guias capacitados para conduzi-los devidamente.

\section{Monitoramento}

Com base no Manual de Ecoturismo de base comunitária do WWF-Brasil (2003), foram pensadas as etapas do sistema de monitoramento e controle de impactos de visitação (MIV) para a Trilha Serra Furada.

A primeira etapa consiste na montagem da equipe de trabalho, na qual pode ser composta por funcionários da própria FATMA, juntamente com a colaboração de integrantes da comunidade Serra Furada, assim como se podem estabelecer convênios com instituições de ensino e pesquisa. Essas incluem organização, como: a Universidade do Sul de Santa Catarina - UNISUL em Tubarão e/ou a Universidade do Extremo Sul Catarinense - UNESC em Criciúma.

Quando a equipe estiver estabelecida, o segundo passo é revisar a legislação e as políticas de conservação, de turismo e de uso do solo pertinentes ao local. O propósito é garantir que todos os seus integrantes estejam cientes das leis das esferas 

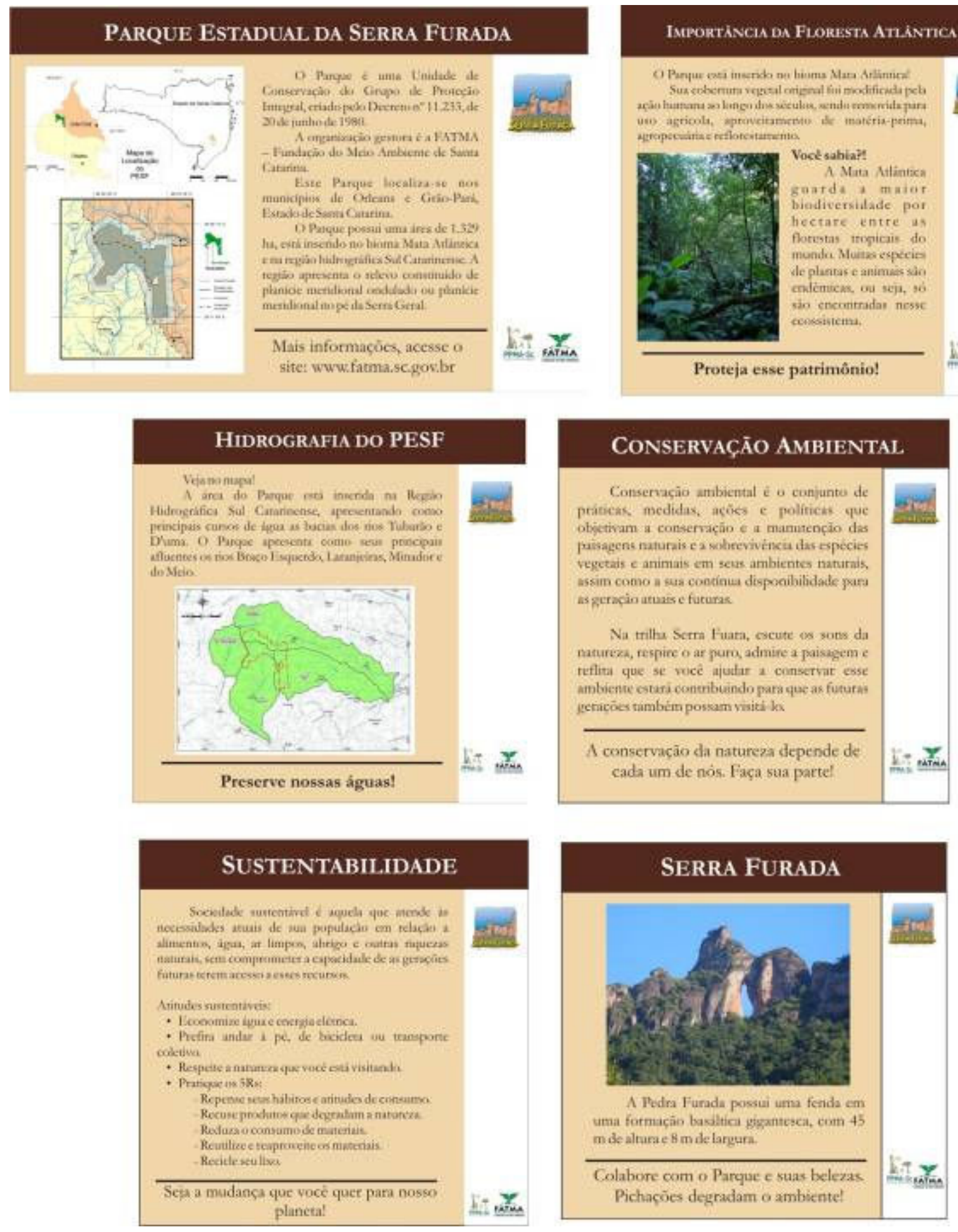

Figura 6 - Sugestão de algumas placas de interpretação ambiental para a Trilha. 
federal, estadual e municipal, bem como assegurar que as atividades a serem desenvolvidas para o uso recreativo não estejam em contradição com as normas vigentes ou com os costumes locais. Além disso, deve-se aproveitar as políticas que beneficiem e incentivam a atividade ecoturística.A análise e reelaboração dos objetivos da Trilha Serra Furada é um procedimento essencial, pois as demais etapas do monitoramento e de avaliação dos impactos de visitação dependerão desses objetivos. "Quanto mais específicos os objetivos, mais fácil será o passo seguinte e, quão mais importante, mais claro será para os responsáveis identificar como deve ser utilizado o local visitado" (MITRAUD, 2003, p. 322).

A partir dos objetivos da trilha devem-se definir os indicadores, pois através deles, estabelecem-se itens ou aspectos para o monitoramento de alterações, possibilitando a prevenção de danos que podem ser irreversíveis. Segundo Lechner (2006, p.94), os indicadores permitem que o administrador enfoque variáveis que reflitam as condições da trilha, possibilitando um foco importante e um uso direcionado dos recursos. Para o monitoramento e a avaliação da Trilha Serra Furada, a proposta contempla os seguintes indicadores:

1. variáveis sociais, que refletem os efeitos no meio ambiente provocados pelo comportamento dos visitantes, ou ganhos de conhecimentos, mudança de valores e satisfação. Indicadores de uso adequado ou inadequado da trilha poderão ser avaliados com observações da ocorrência de: vandalismo; quantidade de lixo; alargamento do caminho da trilha por visitantes; satisfação e percepção sobre diferentes aspectos; conflitos entre a comunidade e os visitantes; e, uso para atividade ilegais/indesejáveis como caça e extração ilegal de algum elemento da natureza, entre outros.

2. variáveis físicas, que representam as alterações causadas no solo em virtude do pisoteio na trilha, tais como: compactação e pH do solo; quantidade de húmus; área de solo desnudado; erosão e transporte do solo, assim como drenagem e química do solo.

3. variáveis biológicas, que mostram as condições da fauna e flora ao longo do caminho, tais como: perda de vegetação ao longo da trilha; introdução de espécies invasoras ao longo da trilha; altura das plantas; extensão da vegetação doente; extensão de árvores com cicatrizes ou mutiladas; raízes expostas e frequência de avistamento de fauna.

Para cada indicador, faz-se necessário estabelecer os limites aceitáveis de mudanças ou alterações, que podem ser entendidos como um determinado nível de uso de uma área. Trata-se do que uma área pode suportar sem causar danos significati- 
vos aos recursos e sistemas ecológicos que são necessários para o seu equilíbrio, garantindo a qualidade da experiência do visitante.

A seguir, determina-se a capacidade de carga da Trilha, ou seja, estabelece-se uma previsão da capacidade de suporte através de um limite de visitações, a fim de evitar ameaças e riscos à UC. Com base no Manual de Ecoturismo de base comunitária do WWF-Brasil (2003), calculou-se a capacidade de carga para a Trilha, sugerindo-se que os grupos tenham de 10 a 12 integrantes.

Após a conclusão das etapas iniciais, deve-se elaborar uma matriz de monitoramento, contendo todas as informações sobre a área de visitação, assim como os objetivos gerais e específicos da Trilha, seus indicadores, parâmetros aceitáveis de impactos e informações sobre a coleta e análise dos dados (ver matriz na próxima página).

Outra etapa muito importante do monitoramento é capacitar a equipe de trabalho responsável a compreender o MIV, seus objetivos e metas, assim como a utilizar os materiais em campo e analisar os dados. Sugere-se que seja estabelecido um cronograma de implementação, com visitas periódicas, preferencialmente durante um ano, que possa abranger a coleta de dados durante todas as estações do ano.

Com a equipe capacitada para o monitoramento poderá haver a coleta dos dados iniciais com o intuito de ajustar e adaptar os instrumentos utilizados e a forma com que as informações serão compiladas. Esta etapa ajuda na adequação dos trabalhos que serão realizados pela equipe responsável pelo MIV. Esta é a fase em que se deve consultar a matriz de monitoramento, atribuindo-se quais indicadores serão analisados e quem será o responsável.

Por fim, deve-se comparar os dados coletados com os parâmetros aceitáveis de impactos negativos. Para tanto, serão indispensáveis discussões dos problemas, elaboração de propostas e/ou alternativas de solução, decisões e planejamento de ações.

Promover discussões e definir ações para corrigir ou prevenir impactos de visitação exige organização e interação da equipe de trabalho. Logo, sugere-se que, quando forem observados parâmetros inaceitáveis, deve-se reunir a equipe de trabalho para discutir as prováveis causas e possíveis soluções.

A seguir, sugere-se a matriz de monitoramento, apresentando os objetivos e os indicadores propostos. 
Aguiar, P.W.; Padua, S.M.; Gomes, M.A.O.; Uezu, A.

\section{MATRIZ DE MONITORAMENTO - Parte 1}

(Descrição de objetivos, indicadores e parâmetros aceitáveis de mudança) IDENTIFICAÇÃO DA TRILHA: Trilha Serra Furada

\section{OBJETIVO GERAL:}

Conectar o caminho principal à pedra furada, proporcionando aos visitantes a oportunidade de obter experiências recreativas e educativas por meio do contato e da interpretação com a natureza.

\begin{tabular}{l|l} 
I1 - Vandalismo & \\
\hline I2 - Quantidade de lixo no local & \\
\hline I3 - Alargamento da trilha pelos visitan- & \\
tes para evitar lamaçais & \\
\hline I4 - Satisfação do visitante & \\
\hline I5 - Percepção do visitante quanto à tri- & \\
Iha e impacto ambiental & \\
\hline Continua... &
\end{tabular}

MATRIZ DE MONITORAMENTO - Parte 2

(Elementos de orientação para coleta e compilação de dados)

TRILHA SERRA FU- $\mid$ NOME DO RESPONSÁVEL: __ Có-

\begin{tabular}{|c|c|c|c|c|c|c|}
\hline \multirow{2}{*}{$\begin{array}{l}\text { DATA } \\
\text { DACO- } \\
\text { LETA }\end{array}$} & \multirow{2}{*}{$\begin{array}{l}\text { LOCALIZA- } \\
\text { ÇÃO DO PRO- } \\
\text { BLEMA }\end{array}$} & \multicolumn{4}{|c|}{ Marque as unidades de cada problema } & \multirow{2}{*}{$\begin{array}{c}\text { COMENTÁ- } \\
\text { RIOS }\end{array}$} \\
\hline & & Li- & Vandalis- & Ero- & Reclama- & \\
\hline & & & & & & \\
\hline & & & & & & \\
\hline & & & & & & \\
\hline & & & & & & \\
\hline & & & & & & \\
\hline
\end{tabular}

\section{Considerações Finais}

Embora o ecoturismo tenha se expandido em todas as regiões do Brasil, ainda há inúmeros lugares com amplo potencial para que seja desenvolvido, e que precisam se beneficiar quando descobertos. 
O potencial do ecoturismo no Brasil é grande pela riqueza ambiental encontrada em todo o território nacional, mas se justapõe ao desafio de gestão que as áreas naturais enfrentam, principalmente as UCs, que carecem de pessoal especializado, recursos e incentivos para a implantação de programas de visitação. Alguns casos de sucesso com essa atividade, entretanto, mostram ser possível superar a carência de profissionais qualificados para o exercício de uma gestão adequada.

Programas ecoturísticos planejados podem, assim, auxiliar os gestores de áreas protegidas a promoverem alianças entre a conservação da natureza, a valorização da cultura local e a promoção do desenvolvimento econômico. A este propósito, as trilhas interpretativas surgem como meios de integrar aspectos diversos, já que são oportunidades das pessoas terem contato com a natureza e suas belas paisagens, possibilitando mudanças e reformulações de valores, muitas vezes esquecidos pela sociedade.

Além de propiciar o contato do ser humano com as áreas naturais, as trilhas interpretativas induzem à reflexão sobre as atitudes frentes às questões ambientais, além de desafiarem o corpo e a mente, o que permite praticar habilidades pouco exigidas no cotidiano, mas capazes de sensibilizar o ser humano diante da grandeza do planeta.

Porquanto, este trabalho tem a pretensão de fornecer contribuições à implantação de um programa de ecoturismo para o PESF, através de sugestões que abrangem desde a fase de planejamento até a implantação da Trilha Serra Furada, somando subsídios para futuras pesquisas no Parque. Além disso, pretende contribuir para a conservação e a sustentabilidade da biodiversidade, possibilitando uma melhor qualidade de vida para a comunidade local, considerando que o programa proposto aponta procedimentos cientificamente reconhecidos para um ecoturismo de qualidade, baseado no profissionalismo consciente, na democracia participativa e no sucesso da modalidade.

\section{Referências Bibliográficas}

ANDRADE, W.J. Implantação e manejo de trilhas. In: WWF-Brasil. Manual de ecoturismo de base comunitária: ferramentas para um planejamento sustentável. Brasília: WWF Brasil, 2003.

Manejo de trilhas para o ecoturismo. In: MENDONÇA, R.; NEIMAN, Z. (Org.). Ecoturismo no Brasil. Barueri, SP: 2005.

; ROCHA, R.F. Manual de trilhas: um manual para gestores. IF Sér. Reg., São Paulo, n. 35, p. 1-74, maio 2008.

ASSOCIAÇÃO BRASILEIRA DE NORMAS TÉCNICAS - ABNT. Turismo como atividade de caminhada. CB-54. Agosto, 2007.

BRASIL. Ministério do Turismo. Ecoturismo: orientações básicas. Brasília: Ministério do Turismo, 2008. 
Aguiar, P.W.; Padua, S.M.; Gomes, M.A.O.; Uezu, A.

DUAILIB, M. Prefácio. In: JUNQUEIRA, V.; NEIMAN, Z. (Org.). Educação ambiental e conservação da biodiversidade: reflexões e experiências brasileiras. Barueri SP: Manole, 2007.

DRUMM, A.; MOORE, A. Desenvolvimento do ecoturismo: um manual para os profissionais de conservação. Introdução ao Planejamento de Ecoturismo. 2002. v. 1. Disponível em: <http://www.parksinperil.org/files/d 4 a ecotourism development vol1 port.pdf>. Acesso em: 09 set. 2009.

GROOM, M.J.; MEFFE, G.K.; CARROLL, C.R. Principles of conservation biologiy. 3.rd. Massachusetts: Sinauer Associates, 2006.

HESSELBARTH, W.; VACHOWSKI, B.; DAVIES, M.A. Manual de construção e manutenção de trilhas. São Paulo: Governo do Estado de São Paulo. Secretaria do Meio Ambiente, 2009.

JANÉR, A.; MOURÃO, R. Elaboração do produto de ecoturismo. In: WWF-Brasil. Manual de ecoturismo de base comunitária: ferramentas para um planejamento sustentável. Brasília: WWF Brasil, 2003.

LECHNER, L. Planejamento, implantação e manejo de trilhas em Unidades de Conservação. Fundação O Boticário de proteção à natureza. Cadernos de conservação. Curitiba, v. 3, n. 3, p. $1-125$, jun. 2006.

Manejo de trilha. Disponível em: <www.ilhabela.org/trilhas/Prop Manejo.doc $>$. Acesso em: 4 jun. 2009.

MEDAUAR, O. (Org.) Coletânea de legislação ambiental: Constituição Federal. 6. ed. rev., ampl. e atual. São Paulo: Revista dos Tribunais, 2007. 1103 p.

MENDONÇA, R.; NEIMAN, Z. Ecoturismo: discurso, desejo e realidade. In: NEIMAN, Z. (Org.). Meio ambiente, educação e ecoturismo. Barueri, SP: Manole, 2002.

MITRAUD, S. Monitoramento e controle de impactos de visitação. In: WWF-Brasil. Manual de ecoturismo de base comunitária: ferramentas para um planejamento sustentável. Brasilia: WWF Brasil, 2003.

PADUA, S.M. Educação ambiental e participação comunitária: chaves para a conservação da biodiversidade. In: ROURE, M.; PADUA, S. Empreendedores sociais em ações. São Paulo: Cultura Editores Associados, 2001. 264 p.

Programa Integrado de Desenvolvimento Sócio-econômico - PIDSE. Diagnóstico municipal de Grão-Pará. SEPLAN; SEICT \& CEAG-SC. Florianópolis, 1990.

RELATÓRIO TÉCNICO: Mapeamento de unidade de conservação: Parque Estadual da Serra Furada, 2008.

SACHS, I. Caminhos para o desenvolvimento sustentável: idéias sustentáveis. Rio de Janeiro: Garamond, 2002.

mond, 2004.

. Desenvolvimento includente, sustentável sustentado. Rio de Janeiro: Gara- 
Subsídios para o planejamento de trilha no Parque Estadual da Serra Furada (SC).

SÃO PAULO. Secretaria do Meio Ambiente. Gestão de unidades de conservação e educação ambiental. São Paulo: SMA, 2009.

VASCONCELOS, J.M.O. Interpretação ambiental. In: WWF-Brasil. Manual de ecoturismo de base comunitária: ferramentas para um planejamento sustentável. Brasília: WWF Brasil, 2003.

WWF-BRASIL. Manual de ecoturismo de base comunitária: ferramentas para um planejamento sustentável. Brasília: WWF Brasil, 2003.

. Fundo Mundial para Natureza. Unidades de conservação. Disponível em:

<http://www.wwf.org.br/informacoes/questoes ambientais/unidades conservacao/ index.cfm>. Acesso em: 31 ago. 2008.

\section{Agradecimentos}

Agradecemos à coordenadora Cristiana Saddy e aos professores do Mestrado em Conservação da Biodiversidade e Desenvolvimento Sustentável, co-participantes deste trabaIho, bemo com a todos os funcionários da FATMA, que continuamente nos incentivaram, discutiram e aconselharam diversas vezes.

Paula Wronski Aguiar: Escola Superior de Conservação Ambiental e Sustentabilidade, IPE - Instituto de Pesquisas Ecológicas.

Email: paula_cdo@hotmail.com

Link para o currículo Lattes: http://lattes.cnpq.br/2117207653955715

Suzana Machado Padua: Escola Superior de Conservação Ambiental e Sustentabilidade, IPE - Instituto de Pesquisas Ecológicas.

Email: suzana@ipe.org.br

Link para o currículo Lattes: http://lattes.cnpq.br/0615879056028445

Marcos Affonso Ortiz Gomes: Escola Superior de Conservação Ambiental e Sustentabilidade, IPE - Instituto de Pesquisas Ecológicas.

Email: ortizgomes@uol.com.br

Link para o currículo Lattes: http://lattes.cnpq.br/0669376533878230

Alexandre Uezu: Escola Superior de Conservação Ambiental e Sustentabilidade, IPÊ Instituto de Pesquisas Ecológicas.

Email: aleuesu@ipe.org.br

Link para o currículo no CNPQ: http://lattes.cnpq.br/6713151102188789

Data de submissão: 16 de junho de 2010.

Data do aceite: 20 de julho de 2010. 